\title{
Characterization of flocculation by Halomonas sp. B01
}

\author{
Te Wang ${ }^{\mathrm{a}}$, Jian $\mathrm{Li}^{\mathrm{b}}$, Zimin Chang ${ }^{\mathrm{c}}$ and Linghua Zhang ${ }^{\mathrm{d}}$ \\ Environmental Science and Engineering College, Dalian Maritime University, 1 Linghai Road, Dalian, \\ People's Republic of China \\ awt414441794@163.com, ddlzlh2008@163.com
}

Keywords: Ectoine-excreting strain; Flocculation activity; Ectoine; Desulfurized wastewater.

Abstract. In order to improve flocculation activity of microbial flocculants in extreme environments, the resilience protective effect of compatible solute ectoine on the flocculation activity of flocculant was researched in this paper. Moderate halophilic bacterium Halomonas sp. B01 was isolated, screened and identified from the sediment of a saltern pool. The strain could synthesize flocculant and compatible solute ectoine simultaneously which were partially excreted into the fermentation broth during a fermentation process in this paper. The optimal conditions of flocculation activity by Halomonas sp. B01 flocculant were $\mathrm{NaCl} 30 \mathrm{~g} / \mathrm{L}, 30^{\circ} \mathrm{C}$ and $\mathrm{pH}$ 8. Ectoine had significant protective effects of resilience to extracted and purified flocculant in the high salt, high temperatures and alkaline environment. By applying Flocculant/Ectoine co-production fermentation broth by Halomonas sp. B01, the purification treatment of the desulfurized wastewater discharged from the seawater magnesia wet flue gas desulfurization was investigated, the results showed that the removal rate of solid content, turbidity and colority were $91.1 \%, 90.5 \%$ and $71.4 \%$, respectively. The Flocculant/Ectoine co-production fermentation broth by Halomonas sp. B01 had significant effect of purification treatment to the desulfurized wastewater discharged from the seawater magnesia wet flue gas desulfurization.

\section{Introduction}

Compared to the traditional flocculants, microbial-produced bioflocculants are biodegradable, non-toxic and no secondary pollution. However, in industries such as petroleum, natural gas, seawater cooling and leather, the activity of microbial flocculants were reduced significantly because of high salinity, high or low temperatures, extreme $\mathrm{pH}$ and high concentrations of heavy metals etc.[1,2]. The researches on flocculation activity of microbial flocculants in extreme environments attract more attention in recent years.

Under environmental osmotic pressure stress, some moderate halophilic bacteria (such as Halomonas) could synthesize compatible solute ectoine (1, 4, 5, 6-tetrahydro-2-methyl-4-pyrimidine- carboxylic acid), which can mitigate deleterious effects of heat stress, freezing, drying, high salinity, oxygen radicals, radiation, urea and other denaturing agents on the integrity of proteins, nucleic acids, biomembranes and even whole cells [3]. It is reported that the ectoine-excreting Halomonas strain (Halomonas salina DSM 5928T) can synthesize and partially excrete ectoine, ectoine excreted to the extracellular can protect the extracellular macromolecules (such as polysaccharides, proteins, etc.) [4]. Based on this, an ectoine-excreting strain has flocculation activity was screened in this paper; the properties of strain flocculate were investigated in kaolin suspension system of $30 \mathrm{~g} / \mathrm{L} \mathrm{NaCl}$; the resilience protective effect of ectoine on the flocculant was explored; on this basis, the flocculation activity of Flocculant/Ectoine co-production (simultaneous synthesis of flocculant and ectoine in a fermentation process) fermentation broth by the strain on the solid content, turbidity and colority of seawater magnesia wet flue gas desulfurization was investigated.

\section{Materials and methods}

Strain. The strain sample was isolated from the sediment of a saltern pool in Dalian, China. 
Fermentation medium (g/L): glucose 40, $\left(\mathrm{NH}_{4}\right)_{2} \mathrm{SO}_{4} 10$, yeast powder $1, \mathrm{KH}_{2} \mathrm{PO}_{4} 3, \mathrm{~K}_{2} \mathrm{HPO}_{4} 9$, $\mathrm{MgSO}_{4} \bullet 7 \mathrm{H}_{2} \mathrm{O} 0.4, \mathrm{MnSO}_{4} \bullet 4 \mathrm{H}_{2} \mathrm{O} 0.01, \mathrm{NaCl} 60 . \mathrm{pH} 7$. The medium was sterilised at $121{ }^{\circ} \mathrm{C}$ for 20 min (Glucose was sterilized separately at $110^{\circ} \mathrm{C}$ for $15 \mathrm{~min}$ ).

Fermentation method. $1 \%$ strain activation suspensions were inoculated in the shake flasks (300 $\mathrm{mL}$ ) containing $30 \mathrm{~mL}$ medium on a rotary shaker set at $120 \mathrm{rpm}$ and $30{ }^{\circ} \mathrm{C}$ for $72 \mathrm{~h}$.

Denitrification method of flocculation activity. The flocculation activity was determined by using spectrophotometric method [5] under $100 \mathrm{~mL}$ suspension contained $4 \%(\mathrm{w} / \mathrm{v})$ kaolin with the 30 $\mathrm{g} / \mathrm{L} \mathrm{NaCl} .721$ spectrophotometer was used to calculate flocculant rate by absorbance at a wavelength of $550 \mathrm{~nm}$. Flocculation activity was equal to flocculant rate. $\mathrm{F}=(\mathrm{A}-\mathrm{B}) \times 100 \%$. F was flocculant rate; A was the contrast absorbance value; $B$ was the contrast absorbance value contained flocculant.

Denitrification method of ectoine. The ectoine concentration was determined by using liquid chromatography method [4].

Denitrification method of turbidity. The turbidity was determined by using spectrophotometric method [6].

Denitrification method of colority. The colority was determined by Pt-Co colorimetric method [7].

\section{Results and discussion}

Isolation of Flocculant/Ectoine co-production strain. Flocculant/Ectoine co-production strain was isolated and screened from the sediment of a saltern pool in Dalian, China. The isolation was performed repeatedly by streak plate technique until the purified single colony was obtained. 20 single colonies were selected, each strain was cultured and fermented. The fermentation broth was centrifuged at $4{ }^{\circ} \mathrm{C}$ and $15000 \times \mathrm{g}$ for $15 \mathrm{~min}$. The flocculation activity and concentrations of ectoine in fermentation broth were determined. Strain B01 had the highest flocculation activity and concentrations of ectoine which were $32.5 \%$ and $892.1 \mathrm{mg} / \mathrm{L}$, respectively. The strain was identified by $16 \mathrm{~S}$ rDNA analysis of Halomonas bacterium, and named as Halomonas sp. B01. Halomonas sp. B01 could synthesize flocculant and compatible solute ectoine simultaneously which were partially excreted into the fermentation broth during a fermentation process.

Focculation characterization of Halomonas sp. B01 flocculant. The flocculant was extracted and purified from Halomonas sp. B01 fermentation broth. A variety of extraction methods were investigated, and the flocculation activity of fermentation product extracted by the method according to the literature [8] was the highest, the extraction and preparation of flocculant were carried out by this method later. The flocculation activities of flocculant under different $\mathrm{NaCl}$ concentrations, temperature and $\mathrm{pH}$ were determined, respectively, the addition of flocculant was $0.6 \mathrm{~g} / \mathrm{L}$, as depicted in Fig. 1 . The $\mathrm{NaCl}$ concentration in flocculation activity measurement system was adjusted to 0,30 , $60,90,120,150,180,210$ and $240 \mathrm{~g} / \mathrm{L}$. The flocculation activities were the highest $(69.8 \%$ and 69.3\%) when $\mathrm{NaCl}$ concentrations were $30 \mathrm{~g} / \mathrm{L}$ and $60 \mathrm{~g} / \mathrm{L}$, the flocculation activity was $49 \%$ (70.2\% of the highest flocculation activity) when $\mathrm{NaCl}$ concentration increased to $240 \mathrm{~g} / \mathrm{L}$ (Fig. 1a). The strain had the highest flocculation activity under certain $\mathrm{NaCl}$ concentrations and the flocculation activity was less affected by high salt concentrations. The flocculant of strain B01 was salt tolerance flocculant. The temperature in flocculation activity measurement system was adjusted to 10, 20, 25, $30,35,40,45,50,60$ and $70{ }^{\circ} \mathrm{C}$. The flocculation activities were higher (79.6\%, 79.5\% and $\left.77.2 \%\right)$ at $30-40{ }^{\circ} \mathrm{C}$, the flocculation activity was $13.2 \%$ when temperature increased to $70{ }^{\circ} \mathrm{C}$ (Fig. 1b). The optimum temperature was $30^{\circ} \mathrm{C}$. The $\mathrm{pH}$ in flocculation activity measurement system was adjusted to $5,5.5,6,6.5,7,7.5,8,8.5$ and $9{ }^{\circ} \mathrm{C}$. The flocculation activities were higher $(79.6 \%, 81.7 \%, 86 \%$ and $84.2 \%$ ) when $\mathrm{pH}$ were $7-8.5$, the flocculation activity was $60.5 \%$ when $\mathrm{pH}$ increased to 9 (Fig. 1c), $\mathrm{pH}$ was configured using Tris- $\mathrm{HCl}$ buffer in method above. The optimum $\mathrm{pH}$ was 8 . The optimal conditions of flocculation activity by Halomonas sp. B01 flocculant were $\mathrm{NaCl} 30 \mathrm{~g} / \mathrm{L}, 30{ }^{\circ} \mathrm{C}$ and pH 8. 

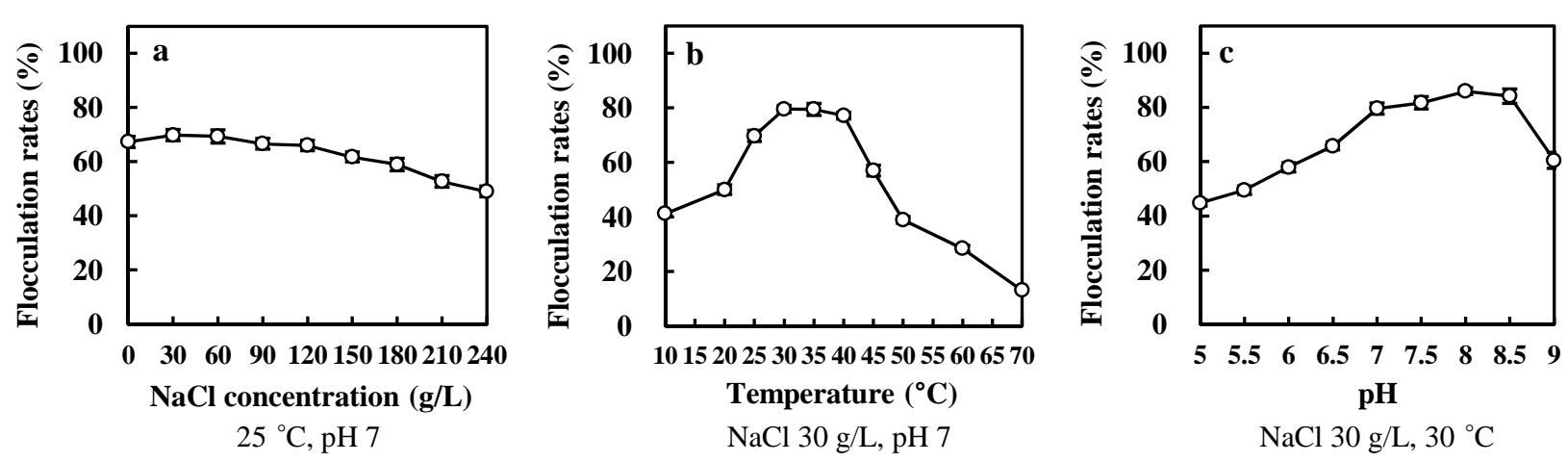

Fig. 1 Focculation characterization of Halomonas sp. B01 flocculant.

Resilience protective effect of ectoine on flocculant. In order to investigate the resilience protective effect of ectoine on flocculant, ectoine was added to flocculation activity measurement system. The concentrations of extracted and purified flocculant and ectoine were $0.6 \mathrm{~g} / \mathrm{L}$ and 300 $\mathrm{mg} / \mathrm{L}$, respectively. The flocculation activities of flocculant and flocculant added ectoine were determined and the results were showed in Fig. 2. The flocculation activity increased by $43.3 \%$ (from $49 \%$ to $70.2 \%$ ) under high salt condition $(\mathrm{NaCl} 240 \mathrm{~g} / \mathrm{L})$, the flocculation activity increased by $354.2 \%$ (from $13.2 \%$ to $59.8 \%$ ) under high temperature condition $\left(70{ }^{\circ} \mathrm{C}\right.$ ), the flocculation activity increased by $36 \%$ (from $60.5 \%$ to $82.2 \%$ ) under alkaline condition (pH 9). The experimental results above showed that ectoine had significant protective effects of resilience to flocculant. The adverse conditions of high salinity, high temperature and alkaline lead to the changes in the spatial configuration of flocculant macromolecule, resulting in decreased flocculation activity [9]. The ectoine contained in the flocculant could enhance the stability of native conformation of flocculant under the inverse environment and then improved flocculation activity.

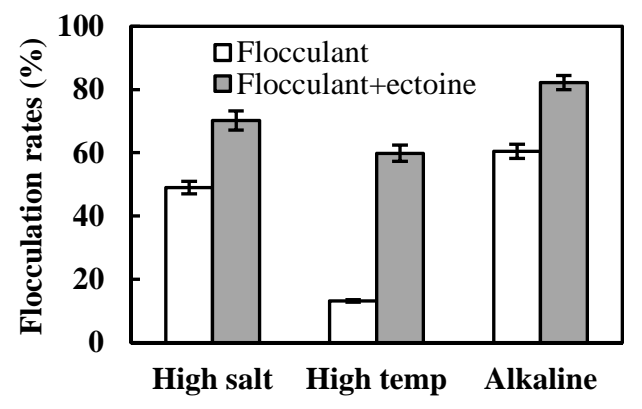

Fig. 2 Resilience protective effects of ectoine on flocculant.

Note: High salt ( $\mathrm{NaCl} 240 \mathrm{~g} / \mathrm{L})$; High temperature $\left(70^{\circ} \mathrm{C}\right)$; Alkaline (pH 9).

The Flocculant/Ectoine co-production fermentation broth applied in extreme environment. Seawater magnesia wet flue gas desulfurization technology was applied to exhaust gas purification in cokes production, smelting, shipping and other industries. Desulfurized wastewater discharged from this treatment process has the characteristics of high salt, high temperature and high fine particle suspension. In this report, the desulfurized wastewater $\left(\mathrm{Cl}^{-} 47.3 \mathrm{~g} / \mathrm{L}, 60^{\circ} \mathrm{C}, \mathrm{pH} 7.8\right.$, solid content 5.6 $\mathrm{g} / \mathrm{L}$ ) discharged from seawater magnesia wet flue gas desulfurization process were purified and treated. The Flocculant/Ectoine co-production fermentation broth was added to desulfurization wastewater (Addition 2\%, flocculant concentration $0.3 \mathrm{~g} / \mathrm{L}$, ectoine concentration $17.8 \mathrm{mg} / \mathrm{L}$ ). The solid content, turbidity and colority were determined and the results were showed in Table 1. As shown in Table 1, the removal rates of solid content, turbidity and colority were $91.1 \%, 90.5 \%$ and 71.4\%, respectively. The Flocculant/Ectoine co-production fermentation broth by Halomonas sp. B01 had significant effect of purification treatment to the desulfurized wastewater discharged from the seawater magnesia wet flue gas desulfurization. 
Table 1 Flocculation effect of Flocculant/Ectoine co-production fermentation broth on desulfurized wastewater

\begin{tabular}{cccc}
\hline Flocculant & Solid content $(\mathrm{g} / \mathrm{l})$ & Turbidity $(\mathrm{FTU})$ & Colority $(\mathrm{mg} / \mathrm{L} \mathrm{Pt})$ \\
\hline Before treatment & $5.6 \pm 0.1$ & $3701.1 \pm 23.9$ & 1750 \\
After treatment & $0.5 \pm 0.1$ & $350.2 \pm 9.9$ & 500 \\
\hline
\end{tabular}

\section{Conclusions}

Moderate halophilic bacterium Halomonas sp. B01 was isolated, screened and identified from the sediment of a saltern pool, could synthesize flocculant and compatible solute ectoine simultaneously which were partially excreted into the fermentation broth during a fermentation process in this paper. The optimal conditions of flocculation activity by Halomonas sp. B01 flocculant were $\mathrm{NaCl} 30 \mathrm{~g} / \mathrm{L}$, $30{ }^{\circ} \mathrm{C}$ and $\mathrm{pH}$ 8. Ectoine had significant protective effects of resilience to extracted and purified flocculant in the high salt, high temperatures and alkaline environment. By applying Flocculant/Ectoine co-production fermentation broth by Halomonas sp. B01, the purification treatment of the desulfurized wastewater discharged from the seawater magnesia wet flue gas desulfurization was investigated, the results showed that the removal rate of solid content, turbidity and colority were $91.1 \%, 90.5 \%$ and $71.4 \%$, respectively. The Flocculant/Ectoine co-production fermentation broth by Halomonas sp. B01 had significant effect of purification treatment to the desulfurized wastewater discharged from the seawater magnesia wet flue gas desulfurization.

\section{References}

[1] S. Sam, F. Kucukasik, O. Yenigun, et al: Bioresour. Technol. Forum Vol. 102 (2011), p. 1788-1794

[2] Q. Wang, H.Z. Liu and K. Zhong: Current Biotechnology. Forum Vol. 1 (2011), p. 318-326

[3] J.M. Pastor, M. Salvador, M. Argandoña, et al: Biotechnol. Adv. Forum Vol. 28 (2010), p. 782-801

[4] L.H. Zhang, Y.J. Lang and S. Nagata: Extremophiles. Forum Vol. 13 (2009), p. 717-724

[5] L.H. Zhang, Y.M. Zhu and Q. Chen: Method for improving the activity of microbial flocculant. (2013), 201310068079.7

[6] N.I. Tananaev and M.V. Debolskiy: Geomorphology. Forum Vol. 218 (2014), p. 63-71

[7] D. Hongve and G. Akesson: Pergamon. Forum Vol. 30 (1996), p. 2771-2775

[8] P.L. WEI: Zhejiang University of Science and Technology. Forum Vol.14 (2002), p. 8-12

[9] Q. Wang, H.Z. Liu and K. Zhong: Current Biotechnology. Forum Vol. 1 (2011), p. 318-326 